\title{
International Trade Strategy Evolution and Pattern Discrimination under the Value Competition Mechanism
}

\author{
Qingxia Dong, Ruoyan Hao *
}

Shandong Vocational and Technical University of International Studies, Rizhao, Shandong, China

* junejunejune666@163.com

\begin{abstract}
International trade theory generally assumes that trade is carried out in the ideal state of perfect competition market and constant return on scale, but the reality is not so. Every economy will formulate some policies to restrict or encourage trade for the sake of maximizing its own trade interests. With the acceleration of globalization, the industrial division of labor, trade benefits and competitiveness of an economy in the global economy are considered from the perspective of value competition mechanism, and the change and future trend of international trade policy under the value competition mechanism are analyzed starting from the introduction of the concept of value competition mechanism. Starting from the integration of the value competition mechanism, focusing on the increase of the added value of the whole industry, combining the technological progress, industry integration and the transformation of factor input. Value through the extension of competition mechanism and integration, the mainstream trade theory deals with the main factors and system variables into a unified multi-factor panel data model framework for empirical analysis, found on the evolution of international trade strategy and pattern identify differences, including system quality and the cost difference split effectively the technological progress, economic benefit and sustainable development and full employment, to maximize the added value of the whole value competition mechanism, and finally realize the improvement of industry international competitiveness.
\end{abstract}

Keywords: International Trade; Value Competition Mechanism; Strategy Evolution; Pattern Discrimination.

\section{Introduction}

A very important part of the value competition mechanism, future trade agreements and international trade policy coordination will be difficult to avoid China. In addition, in fact, most countries are still outside the value competition mechanism, and the existing value competition mechanism is more like the regional value chain from a practical point of view. The dependence of all countries on the value competition mechanism is on the whole showing a deepening trend.

The trade policies formulated by various economies according to their own interest demands have certain externalities, which lead to trade disputes and affect the development of international trade. In order to eliminate contradictions, coordinate the trade policies of various economies and promote trade liberalization, some international organizations represented by the world trade organization (WTO) have made a lot of positive efforts [1,2], but the current situation is not optimistic. To reach a unified trade agreement on a global scale, such as cutting agricultural subsidies of the United States and the European Union, in response to the demands of developing countries [3,4]. In a sign of the revival of the multilateral machinery, the "Bali package", including the trade facilitation agreement, is the least difficult part of the round to negotiate $[5,6]$. It is in WTO developing country member interior also has certain difference. In addition, the profound development of regional economic integration also poses a certain challenge to the multilateral system [7]. Central America has the highest proportion of trade with its artners, followed by Africa, North America and Europe (where the European figures only include trade with external partners, which rises sharply if intra-european trade is included)[8,9]. The coverage of a REGIONAL trade agreement is not necessarily correlated with its absolute size, while the size of trading partners determines the coverage of a regional trade agreement to a greater extent [10]. Value competition mechanism put forward new demands for the global trade and investment rules [11], it requires that the traditional border measures and market admittance problem as the core of trade policy to border measures and regulations in the integration 
as the core of the next generation of trade policy to shift $[12,13]$, narrow diameter based on the traditional mode of production and trade of the trade policy and trade rules no longer apply, need a new definition of new international trade rules based on the value of competition mechanism [14], the so-called "next generation" trade policies.

From the perspectives of theoretical derivation and mathematical demonstration, this paper systematically explores the mechanism and path of the influence of institutional quality and institutional innovation on the evolution of international trade strategies and pattern discrimination. The comprehensive measurement model and evaluation index system of comprehensive evaluation system quality and international trade competitiveness are constructed. This paper constructs a comprehensive index system and evaluation method to systematically analyze and comprehensively measure the quality of the system, which is composed of five levels of indexes including property right system, enterprise system, market system, government management system and foreign-related management system, and makes the system quantification based on scientific theory. Try to through the integrated use of various research methods, especially quantitative analysis method, correlation to do quantitative analysis on international trade and the environment, especially put forward the identify legitimate trade related environmental measures and standard framework of protectionist measures, from the new Angle of view of sustainable development, circular economy, analyze the international trade and environmental issues discussed in this paper.

\section{Research on International Trade Strategy Evolution and Pattern Discrimination Model under the Value Competition Mechanism}

\subsection{Evolution of International Trade Value Competition Mechanism and Strategies}

A growing number of countries and regional trade agreements are adopting zero-tariff policies, and tariffs in developing countries, especially on intermediate goods, are falling, reflecting unilateral national efforts to integrate into the GVC. Through empirical research, the World Bank shows that the proportion of zero-tariff goods in the total import volume is basically increasing. In general, half of the goods imported by developed countries in the world are tariff-free, and some regional trade agreements of developing countries have also adopted an open trading system, as shown in Figure 1.

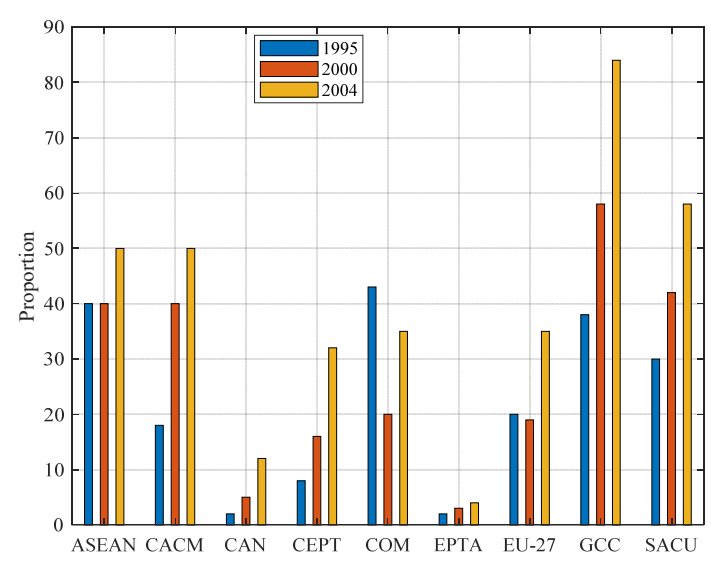

Figure 1. Proportion of zero-tariff goods imports of different countries in total goods imports

The rise of value competition mechanism and the accompanying demand for domestic rules reform have undoubtedly contributed to the proliferation of deep preferential trade agreements in recent years. In many cases, provisions go further than multilateral WTO rules, regulating not only trade between member countries but also investment, industry standards, competition policy, intellectual property, standards and environmental protection. The number of depth clauses in newly established regional trade agreements is shown in Figure 2. It can be seen from the figure that, on the whole, the degree 
of deep provisions or deep integration has been increasing year by year in the past 20 years, which is consistent with the development history of value competition mechanism. This deepening trend brings both opportunities and risks.

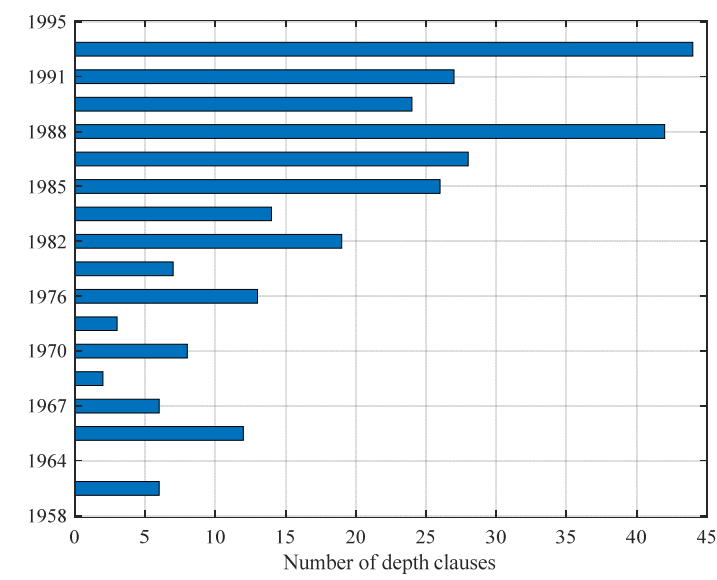

Figure 2. Number of depth provisions in the new regional trade agreement

On the one hand, preferential trade agreements take into account the growing importance of regional and global production networks and encourage further integration through the elimination of tariff and non-tariff trade barriers in trade and investment; In addition, developing countries may benefit from a more stable and reliable trade and investment environment through the upgrading of deep preferential trade agreements, which is necessary for the upgrading of value chains towards higher value-added tasks. Rules in China, on the other hand, wide coverage, leading to the influence of the policy areas beyond the issues directly related to trade, and therefore may be tied to the government in the pursuit of national development strategy goal of hands and feet, for example, some of the dispute settlement mechanism of preferential trade agreements granted to foreign investors in the international arbitration court national rights and the right to require significant compensation.

\subsection{Mechanism and Model of International Trade Pattern Identification}

From an optimistic and idealistic point of view, the best scenario would be the creation of a new World Trade Organization. The realization of this view is based on the following several premises: Large free trade area does not take a long time to achieve the successful conclusion; There is no or only a few cases of the "spaghetti bowl" effect in which consensus is difficult to reach and agreements are intertwined; Conflicting rules can and will be reconciled; The coordination process does not take long; The rules generated by coordination will become the basis of new WTO decisions; The premise that there will be no major problems with the application of rules between members and non-members in large free trade zones can point to an ideal scenario, as shown in Figure 3. New trade rules, especially applied in the field of not covered by the existing rules rules will emerge and become the future W TO the basis of the rules, the situation will be on whether or not TO participate in the global value chain members have a positive impact, both from theory and policy practice should be the ideal result, but the implementation is difficult. As beneficiaries of the global trading system, large developing countries like my own are most looking forward to this outcome.

The summary of the variables used to evaluate the system is made up of the summary of indicators, but the synthesis and summary of indicators are based on the homogeneity of the evaluation indicators. But not all these indicators are homogeneous. On the one hand, the actual value dimensions of each index are different; On the other hand, each evaluation index reflects the different aspects of the system being evaluated. Therefore, the actual use of indicators will be different, can be the total index, can be relative index or average index, so that the actual value of each evaluation index in the order of magnitude difference. 


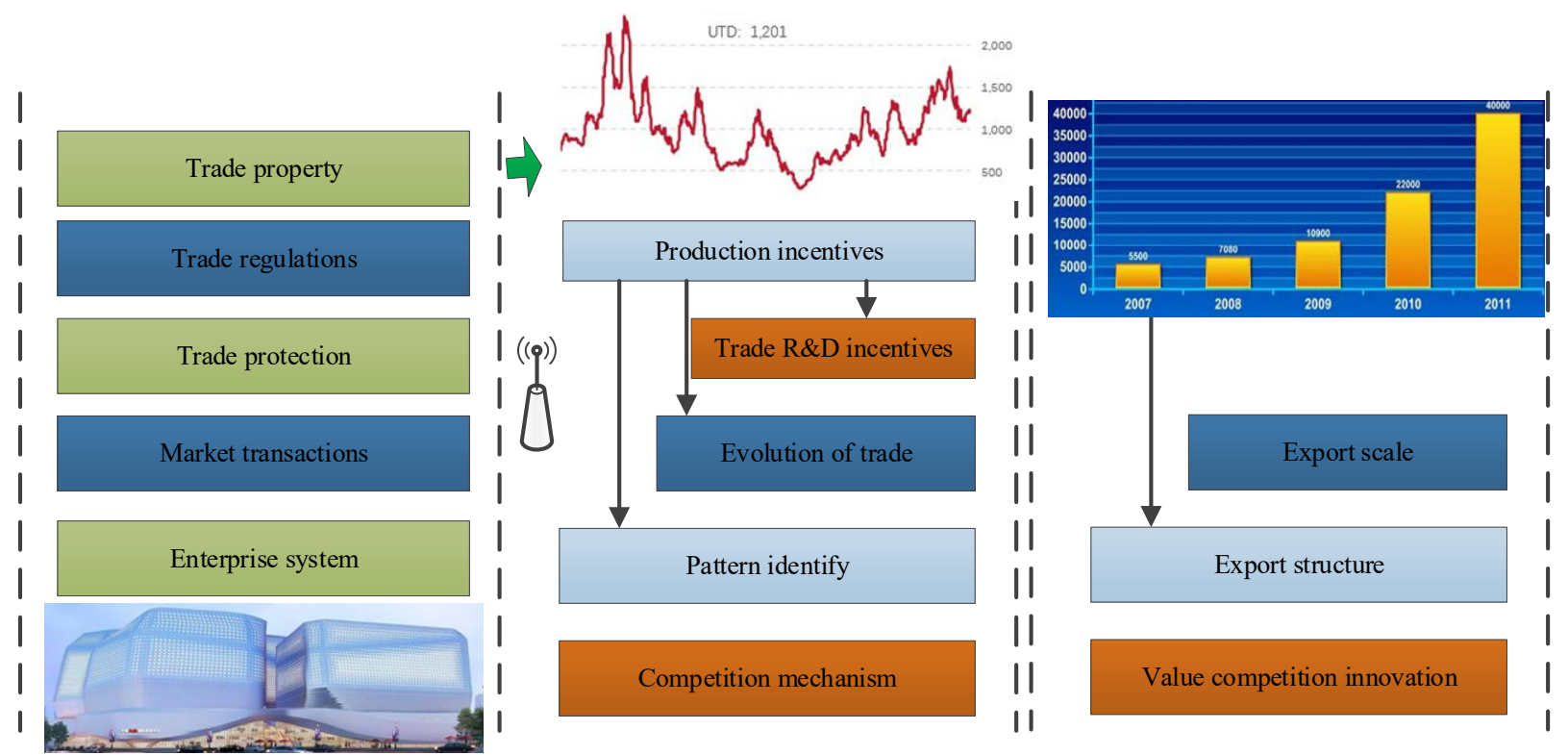

Figure 3. Pattern screening of international trade policy system

First, standardize the raw data. There are many ways to standardize the original index, the most important of which are vector normalization transformation, linear scale transformation and range transformation, etc., because these methods can be found in many comprehensive evaluation literatures. In addition, there is normal standardization, which is often used in statistics but with the assumption that the distribution of data is roughly symmetric. Under the condition of satisfying the basic assumption of symmetric distribution and using normal distribution standardization, the results are more accurate than other standardization methods.

Secondly, the cumulative probability distribution is calculated. In the competitiveness research, it is necessary to make a comparative analysis of each single indicator. In order to provide a basis for comparison between indicators, indicators must be converted into direct comparison. A more reasonable way is to calculate the cumulative probability distribution value, that is, to calculate the cumulative probability distribution value by using standardized values and using normal distribution function. The position of the cumulative probability can indicate the position of this index in all samples.

Finally, the index value of each index is calculated. Among the selected indicators, there are mainly two categories, one is positive index, the other is inverse index. Multiply the probability distribution value of the above-mentioned single index by 10 . If it is a positive index, the value of this index will be used as the score of each region of this single index. If it is an inverse index, the score of each region is calculated by taking the product of 10 minus the probability distribution value and 10 .

International market share is the proportion of the total export of products in the total export of the world, which is a direct indicator to measure the export competitive advantage of a country's $\mathrm{x}$ industry. Y stands for international export volume, and $\mathrm{N}$ stands for export advantage in international trade.

$$
Q=Y^{I} / Y^{W}
$$

Net export is the net balance between the export and import of a certain product of a country. It is the most direct indicator of the competitive advantage of a certain product or industry of a country in international trade.

$$
Q Y=Y_{I}-N_{I}
$$


The relative export advantage index is mainly used to measure the export advantage of a country's certain product or industry relative to the overall export advantage of the country.

$$
R Y B_{I}=\frac{Y_{I} N_{I}}{\sum Y_{I} / \sum N_{I}}
$$

The evolution of international trade strategy focuses on measuring the cost, efficiency and innovative competitiveness of a country's exports from the perspective of per capita export scale. The calculation formula is as follows:

$$
Q Y_{I}=Q Y_{I} / Q Y_{W}
$$

Screening of international trade patterns generally indicates that there is a significant positive relationship between the trade share of a domestic industry and the foreign trade competitiveness of the country. The calculation formula is as follows:

$$
G L=\frac{\sum Y_{I J}+N_{I J}-\sum\left|Y_{I J}\right|}{\sum\left(Y_{I J}+N_{I J}\right)}
$$

Under the division of global value chain, a country's competitive advantage is no longer reflected in the final product and a specific industry, but in the link that the country occupies in the global value chain. Generally speaking, the most competitive countries in specific industries occupy the strategic links with monopoly position, with high added value and rich profits. A few countries with strong competitiveness in a specific industry occupy the oligarchic advantage, with high added value and large profits. Countries with certain competitiveness occupy the link of imperfect competition, with average added value, and can obtain normal profits; However, in countries without international competitiveness, they can only occupy the perfect competition link in the value chain, with small added value and very thin profit. Therefore, the global value chain division of labor makes the change of a country's terms of trade no longer limited to the change of trade structure, but must look at its position in the global value chain division of labor. See Figure 4.

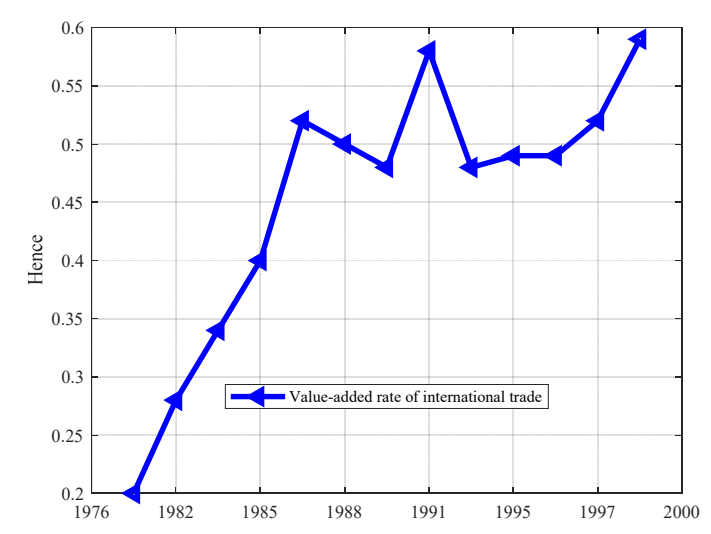

Figure 4. Changes of value-added rate of international trade pattern screening

Trade competitiveness and export scale, export structure, export benefit, export quality, export efficiency, there is a significant positive correlation between export efficiency, among which the trade competitiveness and export innovation are the strongest size second, export quality the least. The impact of trade scale on trade competitiveness is very easy to understand, trade easy scale does not reach a certain level is impossible to be recognized as a trade power, a certain amount of trade can make one the State has a greater say in foreign trade and safeguards its interests. Trade volume to the enhancement of trade competitiveness although. However, it has a great impact, but it is no longer 
the most important factor. The mere rapid expansion of the total volume of trade only promotes the promotion of trade competitiveness is an important aspect, but not the whole, but from the perspective of the international trade development process of each country, such as if excessive pursuit of scale expansion, or trade volume shows unusually high growth, its trade competitiveness is sustainable sex is likely to deteriorate, affecting its long-term international trade competitiveness. At the same time technological innovation competes against trade.

\section{Conclusion}

Competition mechanism in value, quality system, system innovation and efficiency advantage under the endogenous relationship between international trade, when the production process of physicochemical constant cost, profit optimization strategy, and other conditions must, export production efficiency and the efficiency of the products is increasing function of the system of quality, thus institutional quality difference is a determinant of international trade efficiency differences. In a dynamic general equilibrium framework, when other conditions must value the improvement of the competitive mechanism can reduce friction innovation team in the division of labor, improve the efficiency of research and development of the degree of specialization and innovation, leading to the evolution of international trade policy and the system of pattern identify specialization in dependence strong complex high technology product development and export competitive advantage, and form innovation and evolution of international trade strategy and pattern identify curing state is forced to choose simple the comparison of technology innovation advantage, obviously, The evolution of international trade strategy and the change of pattern discrimination based on the value competition mechanism have led to the endogenous changes of high-tech product selection, division of labor structure and innovative competitive advantage among countries.

\section{References}

[1] Rakotoarisoa M A. Trade with Endogenous Market Power Under Asymmetric and Incomplete Information [J]. Journal of Industry, Competition \& Trade, vol.16, no.4, pp.31-48, 2016.

[2] Xie L X, Zhang Q B, Gu J C. Damage evolution mechanism in production blasting excavation under different stress fields[J]. Simulation Modelling Practice and Theory, vol.97, pp.101969-101972, 2019.

[3] Bryan W, Stanley K O, Norman J. Altruists Proliferate Even at a Selective Disadvantage within Their Own Niche[J]. Plos One, vol.10, no.6, pp. e128654-e128662, 2015.

[4] Cuadros M A R. The Non-discrimination Principle and VAT: Rules of Thumb for Trade and Tax PolicyMakers [J]. Global trade and customs journal, vol.11, no.2, pp.62-70, 2016.

[5] Laroche F, Jarne P, Perrot T. The evolution of the competition- dispersal trade-off affects alpha-and betadiversity in a heterogeneous metacommunity[J]. Proc Biol, vol.283, no.1829, pp.20160548-20160562, 2016.

[6] Mccarthy O, Meulengraaf S V D. The principles of equality and non-discrimination under viral attack: Stigma, hate speech, xenophobia, racism and discrimination during the COVID-19 pandemic[J]. Freedom from Fear, vol.2020, no.16, pp.22-27, 2020.

[7] Zhong Y, Lin A, Zhou Z. Spatial Pattern Evolution and Optimization of Urban System in the Yangtze River Economic Belt, China, Based on DMSP-OLS Night Light Data[J]. Sustainability, vol.10, no.10, pp.212-223, 2018.

[8] Gunji M, Endo H. Growth Pattern and Functional Morphology of the Cervical Vertebrae in the Gerenuk (Litocranius walleri): The Evolution of Neck Elongation in Antilopini (Bovidae, Artiodactyla) [J]. Journal of Mammalian Evolution, vol.26, no.2, pp.225-235, 2019.

[9] A L W, B C W A, A D G. Evolution mechanism of synoptic-scale EAP teleconnection pattern and its relationship to summer precipitation in China[J]. Atmospheric Research, vol.214, pp.150-162, 2018.

[10] Yilin L, Chen B, Chen G Q. Carbon network embodied in international trade: Global structural evolution and its policy implications[J]. Energy Policy, vol.139, pp.111316-111323, 2020. 
[11] Budiono G L. Inequality of international trade strategy: Poor and advanced country practices[J]. International Journal of Civil Engineering and Technology, vol.9, no.11, pp.2502-2512, 2018.

[12] Yong-Xiong Z, Liang-Ming W, Lu-Xia Y. A network attack discovery algorithm based on unbalanced sampling vehicle evolution strategy for intrusion detection[J]. International Journal of Computers \& Applications, vol.42, no.1, pp.84-92, 2020.

[13] Jehangir K, Inamullah K, Abdul G. Epidemiological trends and risk factors associated with dengue disease in Pakistan (1980-2014): a systematic literature search and analysis[J]. Bmc Public Health, vol.18, no.1, pp. 745-762, 2018.

[14] Alberto Franco Solís, André F.T. Avelino, André Carrascal-Incera. The evolution of household-induced value chains and their environmental implications[J]. Ecological Economics, vol.174, pp.106667-10675, 2020 . 